\title{
A zona costeira e a produção do ambiente litorâneo cearense: o município de Caucaia-Ceará, Brasil.
}

\author{
The coastal area and the production of Cearense coastal environment: the city of \\ Caucaia, Ceará, Brazil.
}

MENEZES $^{1}$, K. W. S.; ZANETTE ${ }^{2}$, F. R.; GRANGEIRO ${ }^{3}$, C. M. M.

karinnewendy@gmail.com;

\begin{abstract}
Resumo
Este trabalho objetiva entender como se ocorreu a produção do ambiente costeiro no estado do Ceará, especificamente no município de Caucaia, que está inserido na Região Metropolitana de Fortaleza. Para isso, foi realizado um levantamento teórico e metodológico que fomentasse uma discussão sobre a zona costeira, uso e ocupação do litoral cearense, e o município de Caucaia, associados ao trabalho de campo para o reconhecimento da área de estudo. Deste modo, buscou-se fazer uma análise da produção do ambiente litorâneo, pelo fato de apresentar conflitos de usos e interesses. Constatou-se que Caucaia está entre os municípios da RMF mais procurados para atividades turísticas, assim como foram identificados problemáticas ambientais e socioespaciais nas formas de uso e ocupação do litoral Caucaiense.
\end{abstract}

Palavras-chave: zona costeira, produção do espaço, Caucaia.

\begin{abstract}
This study aims to understand how it was the production of the coastal environment in the state of Ceará, specifically in the municipality of Caucaia, which is housed in the Metropolitan Region of Fortaleza. For this, we performed a theoretical and methodological survey that would foster a discussion of the coastal zone, use and occupation of Ceará, and the municipality of Caucaia, associated with the field work for the recognition of the study area. Thus, it sought to analyze the production of the coastal environment, in that present conflicts of uses and interests. It was found that Caucaia is among the RMF of the most popular cities for tourism activities, as identified environmental and socio-spatial problems in the forms of use and occupation of Caucaiense coast.
\end{abstract}

Keywords: coastal zone, production of space, Caucaia.

\section{INTRODUÇÃO}

A zona costeira, em uma escala global, apresenta características naturais diferenciadas e particularidades nas diferentes formas de ocupação e possibilidades de uso do solo. A zona costeira do Brasil é um patrimônio cultural definido pelo parágrafo 4o do art. 225 da Constituição Federal, que se estende por mais de 8.500 km voltados para o Oceano Atlântico. (MMA, 2014).

Consisti no lugar de encontro de três sistemas naturais diferentes: a hidrosfera, a litosfera e a atmosfera, por isso, o ambiente apresenta uma dinâmica complexa que se traduz por uma variedade de feições geomorfológicas, como as praias, dunas, falésias e os estuários. (VASCONCELOS, 2005)

De acordo com o IBGE (2010) no Brasil, a maior parcela da população reside em cidades litorâneas, e algumas das capitais brasileiras, também se localizam na zona costeira, a 
exemplo das metrópoles: Fortaleza, Salvador, Recife e o Rio de Janeiro. Deste modo, temos que repensar o litoral, para que ele não seja interpretado apenas como fonte de recursos.

O município de Caucaia faz parte da Região Metropolitana de Fortaleza, e dispõe da maior extensão territorial da RMF, estando integrado a este processo de metropolização desde a década de 1970. (AMORA, 1999)

Caucaia está localizada ao Norte do estado do Ceará, com latitude $3^{\circ} 44^{\prime} 10^{\prime \prime} \mathrm{e}$ longitude de 38 39' e 11',; faz limites com o Oceano Atlântico e São Gonçalo do Amarante ao norte, Maranguape ao sul, Maranguape, Maracanaú e Fortaleza a Leste e São Gonçalo do Amarante, Pentecoste e Maranguape a oeste, com uma área de 1227,9 km², situando-se a $20 \mathrm{~km}$ de Fortaleza, capital do estado. (IPECE, 2013). A figura 01 compreende a localização geográfica de Caucaia no Estado do Ceará.

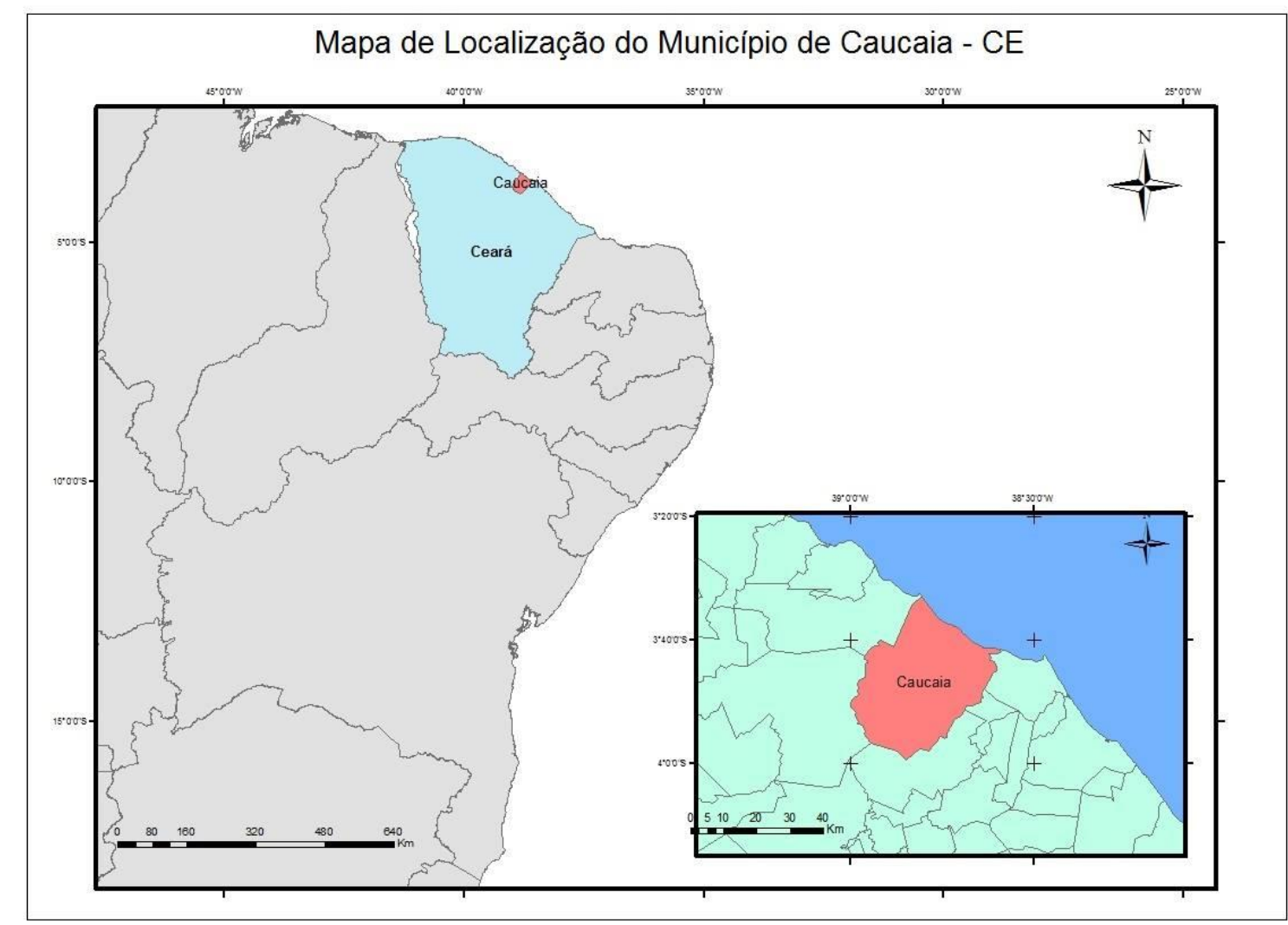

Figura 01: Localização do município de Caucaia-CE. Fonte: Elaborado pelos autores (2016).

Caucaia faz parte Bacia Hidrográfica Metropolitana, com características naturais predominantes do Complexo Vegetacional da Zona Litorânea, Cerrado e Caatinga Arbustiva Densa, com clima Tropical Quente Semiárido Brando, Tropical Quente Sub-úmido e Tropical Quente Úmido, com pluviosidade de $1243,2 \mathrm{~mm}$ e a temperatura média de $26^{\circ}$ a $28^{\circ}$, tendo seu período chuvoso, sobretudo, entre os meses de janeiro a maio. (IPECE, 2013) 
De acordo com Araújo (2010, p. 57), Caucaia, entre os municípios da RMF, é um dos mais explorados e valorizados pelo turismo, com infraestruturas de hotéis e pousadas nas praias de Pacheco, Cumbuco, Tabuba, Vila dos Pescadores, Icaraí e Lagoa do Banana, e "a atividade turística transforma a feição das praias, antigas vilas de pescadores em localidades urbanizadas e valorizadas, de intensa mobilidade populacional em finais de semana”.

A figura 02 refere-se à visualização da praia do Cumbuco, em Caucaia-CE, um dos ambientes litorâneos mais frequentados pelos moradores da Região Metropolitana de Fortaleza.

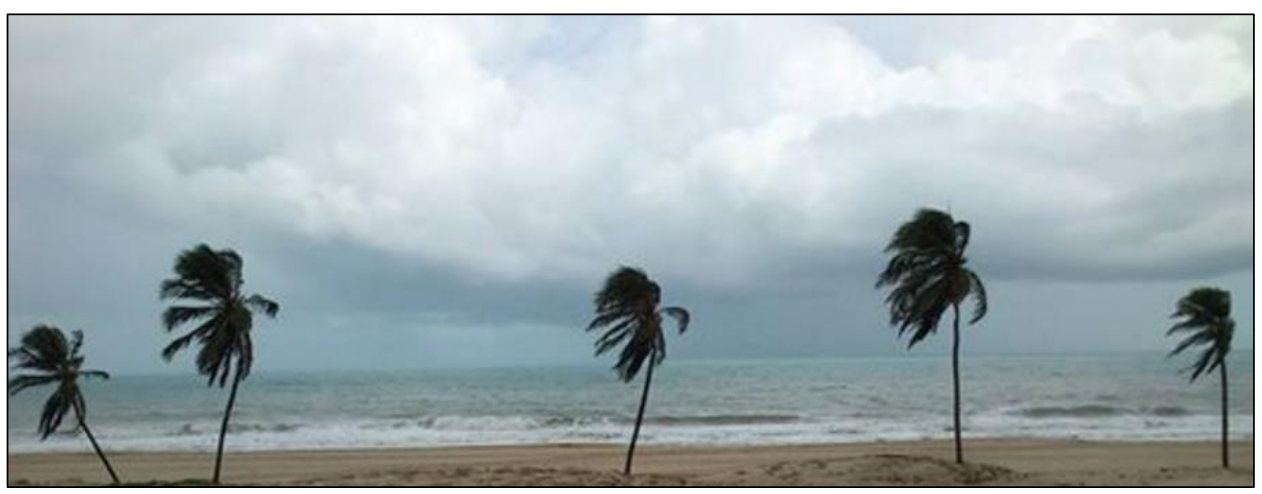

Figura 02: Praia do Cumbuco-CE. Fonte: Menezes, 2015.

\section{METODOLOGIA}

Os procedimentos adotados na pesquisa consistiram, primeiramente, no levantamento bibliográfico, com a utilização de livros, artigos e trabalhos acadêmicos disponibilizados pela Universidade Estadual do Ceará (UECE), Universidade Federal do Ceará (UFC), e pelo Instituto Brasileiro de Geografia e Estatística (IBGE).

A segunda etapa da pesquisa correspondeu a realização de um campo no litoral oeste do estado, no município de Caucaia, para o reconhecimento da área de estudo. Contudo, devido à dimensão territorial do município de Caucaia, no percurso organizado, visitou-se as praias de Iparana, Icaraí e Cumbuco.

\section{RESULTADOS E DISCUSSÃO}

Nas regiões costeiras ocorrem conflitos de usos e interesses, que são atribuídos basicamente aos tipos de atividades que tem destaque na economia de um país, como por exemplo, o Brasil, com as suas atividades de lazer, turismo, habitação, indústria, comércio, e de transporte marítimo de mercadorias. Segundo Araújo (2010, p. 49) “o Ceará, em particular, conta com massivos investimentos federais para a infraestrutura turística, na Capital e em localidades litorâneas (Aeroporto Internacional, Rodovias Litorâneas). ” 
As regiões litorâneas precisam ser pensadas para além das atividades econômicas, pois elas apresentam além de uma importância ambiental e uma dimensão social, e o litoral é uma zona com múltiplos usos, com diferentes tipos de uso e ocupação do solo, conforme Grangeiro (2012):

[...] estamos assumindo a postura da não separação sociedade-natureza como fundamento de uma reflexão e da definição de do ambiente humano litorâneo, de tal modo que, supomos que estas delimitações - de ordem puramente natural, ou a partir de critérios sociais - são instrumentos de aproximações do que seja concretamente o litoral como um ambiente humano. (GRANGEIRO, 2012, p. 36)

Moraes (2007) faz abordagens sobre os espaços litorâneos e levanta interrogações acerca das particularidades da localização litorânea; os fatores contribuem para que a zona costeira apresente particularidades geográficas, como as evidenciadas na zona costeira brasileira como podem observar na citação abaixo:

Os litorais abrigam, portanto, um contingente populacional denso e concentrado, ao qual corresponde uma concentração de atividades, localizando-se também a beira-mar boa parte das instalações industriais em operação hoje no mundo. $\mathrm{O}$ caráter concentrado do povoamento costeiro, de claro perfil urbano, emerge como uma característica internacional que reforça a designação tipológica da localização litorânea. (MORAES, 2007, p. 21)

Tendo o intuito de preservar na zona costeira ambientes como os estuários, por exemplo, pelo fato de apresentarem diversas tipologias quanto às formas de uso e ocupação, foram criadas diversas unidades de conservação em todo o território brasileiro; no Brasil a responsabilidade de gestão das Unidades de Conservação - UC's é principalmente dos governos estaduais. Contudo, a tomada de decisões dessas unidades não deve ser realizada apenas pelos órgãos gestores, mas com a participação da sociedade civil, como define o Sistema Nacional de Unidades - SNUC. (MMA, 2014)

A partir dessas explanações, é possível compreender que a concentração de atividades no ambiente litorâneo e a preocupação com a preservação desses ambientes, fazem parte de um processo bem mais amplo, que inclui os modos de produção capitalista em todo o território brasileiro, sendo este processo, histórico, político e social. Corrêa (2005) afirma que:

A grande cidade capitalista é o lugar privilegiado de ocorrência de uma série de processos sociais, entre os quais há acumulação de capital e a reprodução social tem importância básica. Estes processos criam funções e formas espaciais, ou seja, criam atividades e suas materializações, cuja distribuição espacial constitui a própria organização espacial urbana. (CORRÊA, 1995, p. 36)

A natureza passa a ser vista como mercadoria, por meio da relação da sociedade com a natureza mediada pelo trabalho e pela técnica, que transforma a natureza primeiramente em 
recurso, e tão logo mercadoria, relação na qual a sociedade não se considera integrante da natureza, mas distinta e sobrepõe-se a ela.

A natureza passa a ser considerada apenas como fonte de recursos, e todo este processo influencia na organização socioespacial, que intervém como no caso brasileiro, nos modos de utilização desse território por meio desses agentes produtores do espaço, como no caso da zona costeira do estado do Ceará.

Segundo Morais et al. (2006) o estado do Ceará tem uma linha de costa de $573 \mathrm{~km}$ de extensão, devido as suas dimensões, existem diferenciações na paisagem litorânea, como as dunas, falésias, lagoas, rios e estuários, tanto no litoral leste, quanto no oeste do estado.

No município de Caucaia, até os dias atuais, residem comunidades pesqueiras e à etnia indígena Tapeba, que além de enfrentarem um processo de desterritorialização, sofrem com os conflitos ocasionados pelo o processo de expansão do espaço urbano, que influencia, por exemplo, na forma como eles lidam com a natureza.

A ocupação do litoral de Caucaia não foi homogênea, Araújo et al. (2010) estabelecem a ocupação litorânea de Caucaia a partir de três fazes distinta, a primeira que ocorreu até a metade do século XX, principalmente nas praias do Cumbuco, Icaraí e Tabuba com a ocupação caracterizada pela aldeia de pescadores, a segunda de 1950 à aproximadamente 1980, com a ocupação nas praias do Icaraí e Iparana, principalmente de casas de veraneio, a última estende-se até os dias atuais, onde concentram-se no Cumbuco e na Tabuba grandes empreendimentos turísticos.

Em Iparana, existem muitas implicações nas formas de usos e ocupação. $\mathrm{Na}$ pesquisa em campo constatamos a presença de duas comunidades, primeiramente a comunidade do Boi Choco, que se localiza na praia, com destaque para atividade pesqueira; e o Guaié, que está situado na Área de Proteção Ambiental do Estuário do Rio Ceará. A figura 03 refere-se à praia de Iparana, Caucaia-CE.

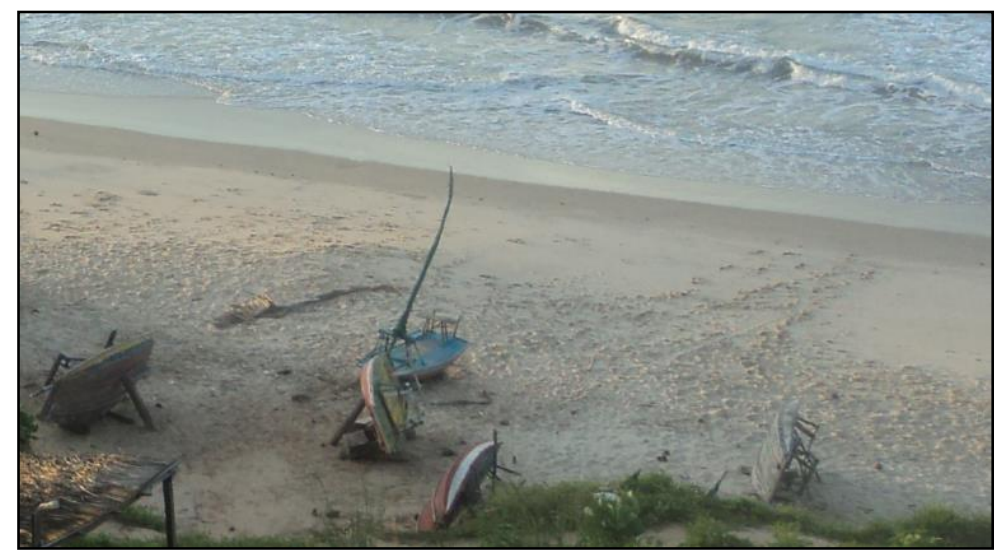

Figura 03: Praia de Iparana em Caucaia-CE. Fonte: Menezes, 2014. 
Na pesquisa em campo, podemos constatar que a permanência dessas comunidades está em constante tencionamento com usos do solo mais intensivos em capital, na consolidação da ocupação de Iparana houve um movimento de expansão de segunda residência de uma cla sse média excluída das principais praias turísticas. Soma-se a isso a crescente inserção do município de Caucaia nos circuitos turísticos do Estado do Ceará, que reforça a pressão sobre a terra como mercadoria. O futuro reserva uma ampla gama de tensões e conflitos pela apropriação do espaço dessas áreas costeiras.

\section{CONSIDERAÇÕES FINAIS}

A ocupação do litoral município de Caucaia não ocorreu de forma homogênea, e apresenta usos e interesses diversificados. De acordo com Araújo et al. (2010), as mudanças nos espaços litorâneos são produtos das políticas públicas adotadas no estado do Ceará, e as atividades turísticas nestas áreas, apesar de movimentarem a economia local, interferem no cotidiano das populações que vivem nestes espaços.

A Região Metropolitana de Fortaleza - RMF, segundo Teles (2005) foi uma das primeiras regiões metropolitanas brasileiras, sendo instituída através da Lei Complementar Federal $n^{\circ} 14$ de 08 de junho de 1973. A ocupação no litoral cearense é mais concentrada nos municípios que integram a RMF, como nos municípios de Caucaia e Maracanaú, este último, embora não faça fronteira com o mar, está enquadrado na zona costeira do Ceará.

A urbanização dos municípios litorâneos como Caucaia e a sua inserção na região metropolitana faz com que as problemáticas ambientais e socioespaciais identificadas nas formas de uso e ocupação da zona costeira relacione diferentes agentes produtores do espaço, e envolva tanto as questões sociais, quanto as políticas e econômicas.

\section{REFERÊNCIAS}

AMORA, Z. B. O Espaço urbano cearense: breves considerações. In: AMORA, Z. B. (org). O Ceará: enfoques geográficos. Fortaleza, Editora: FUNECE, 1999. 143 p.

ARAÚJO, A.M.M. Fortaleza, metrópole regional: trabalho, moradia e acumulação. Fortaleza, EDUECE, 2010. 208 p.

ARAÚJO, E. F. de; PEREIRA, A. Q.; PAUlA, E. O. de. TURISMO LITORÂNEO NA METRóPole CEARENSE: O CASO DE CAUCAIA, CEARÁ, BRASIL. Conex. Ci. e Tecnol. Fortaleza/CE, v. 4, n. 1, p. 72-81, nov. 2010.

BRASIL. Instituto Brasileiro de Geografia e Estatística - IBGE. Caucaia. Disponível em: <http://www.censo2010.ibge.gov.br/sinopse/index.php?dados=10\&uf=00> Acesso em 01 de julho de 2014. 
BRASIL. Ministério do Meio Ambiente - MMA. Unidades de Conservação. Disponível em: $<$ http://www.mma.gov.br/areas-protegidas/unidades-de-conservacao/plano-de-manejo 15/01/2013>. Acesso em 15 de janeiro de 2014.

BRASIL. Ministério do Meio Ambiente - MMA. Zona Costeira. Disponível em: <http://www.mma.gov.br/gestao-territorial/gerenciamento-costeiro/a-zona-costeira-e-seusm\%C3\%BAltiplos-usos/caracteristicas-da-zona-costeira>. Acesso em 12 de abril de 2014.

CEARÁ. Instituto de Pesquisa e Estratégia Econômica do Ceará - IPECE. Perfil Básico. Disponível em: <http://www.ipece.ce.gov.br/publicacoes/perfil_basico/pbm-2013/Caucaia.pdf>. Acesso em 11 de junho de 2014.

CORRÊA, R. L. O espaço urbano. São Paulo: Ática, 1995. 94 p.

GRANGEIRO, C. M. M. Meio ambiente litorâneo e urbanização: o ambiente produzido na costa leste da cidade de Fortaleza - Ceará. Tese de doutorado apresentada ao Programa de Pós-Graduação em Geografia da Universidade Estadual do Ceará, Fortaleza, 2012. 238 p.

MORAES, C. A. R. Contribuição para a gestão da zona costeira do Brasil: elementos para uma geografia do litoral brasileiro. São Paulo: Annablume, 2007. 232 p.

MORAIS, J. O.; FREIRE; G. S. S.; PINHEIRO; L. de S.; SOUZA; M. J. N. de; CARVALHO; A. M. de; PESSOA; P. R. S.; OLIVEIRA; S. H. M. Ceará. In: MUEHE, D. (org.). Erosão e progradação no litoral brasileiro. Brasília: MMA, 2006. 131-154p.

TELES, G. A. Dinâmicas Metropolitanas Contemporâneas: Caucaia na Região Metropolitana de Fortaleza. Dissertação de mestrado apresentada ao Programa de PósGraduação em Geografia da Universidade Estadual do Ceará, Fortaleza, 2005. 176p.

\section{AGRADECIMENTOS}

À professora e orientadora Claudia Maria Magalhães Grangeiro (In Memoriam), pelos conhecimentos compartilhados e pela amizade;

Ao Programa de Educação Tutorial - PET Geografia da Universidade Estadual do Ceará UECE;

À Coordenação de Aperfeiçoamento de Pessoal de Nível Superior - Capes.

Recebido em: 14/08/2016

Aceito para publicação em: 01/10/2016 